\title{
Combining World Class Manufacturing system and Industry 4.0 technologies to design ergonomic manufacturing equipment
}

\author{
Marianna Ciccarelli ${ }^{1}$ (I) $\cdot$ Alessandra Papetti ${ }^{1}$ (i) $\cdot$ Federica Cappelletti ${ }^{1}$ (I) $\cdot$ Agnese Brunzini $^{1}$ (i) $\cdot$ \\ Michele Germani ${ }^{1}$ (D)
}

Received: 17 May 2021 / Accepted: 24 December 2021 / Published online: 12 January 2022

(c) The Author(s) 2022

\begin{abstract}
In the era of the fourth industrial revolution, human has still a central role. Manufacturing industries have to deal with human sustainability in order to guarantee workers' health and well-being. Several studies have proved the importance of ergonomics in workplace design and the benefits related to the adoption of the human-centered approach. The enabling technologies of Industry 4.0 are changing the role of the operator and can support him from a physical and cognitive point of view. On the other hand, companies are increasingly implementing lean philosophies, such as World Class Manufacturing, to maintain their competitiveness by reducing wastes and costs. However, the need arises for a comprehensive methodology to support the design of manufacturing equipment considering human factors by integrating Industry 4.0 technologies and World Class Manufacturing elements. It aims at improving both ergonomic and efficiency aspects of the workstation. The proposed methodology allows identifying and in-depth analyzing the problem, thus finding and implementing a solution that complies with all the requirements and constraints defined. Each step of the methodology can be strengthened by Industry 4.0 technologies. The methodology has been experimented in a real case study with a global company of agriculture and industrial vehicles, leading to the design and implementation of a new equipment. Relevant benefits in terms of ergonomics, efficiency, and process standardization have been achieved.
\end{abstract}

Keywords Human-centered manufacturing · Equipment design · Ergonomics · World class manufacturing · Workplace organization pillar · Industry 4.0

\section{Introduction}

Today's worldwide market requires a business to be dynamic and able to fast-move to adjust itself and satisfy end-users needs. The central role of the customer, now perceived as the actor pulling industrial activities, together with consequences
Marianna Ciccarelli
m.ciccarelli@staff.univpm.it
Alessandra Papetti
a.papetti@staff.univpm.it
Federica Cappelletti
f.cappelletti@pm.univpm.it
Agnese Brunzini
a.brunzini@staff.univpm.it
Michele Germani
m.germani@staff.univpm.it

1 Department of Industrial Engineering and Mathematical Sciences, Università Politecnica Delle Marche, Ancona, Italy due to globalized markets, implicate changes in terms of business management. All sectors perceive these drivers; in particular, the automotive sector is aware that its competitive realm is shifting away from traditional classifications based on firms' production systems or geographical homes. Companies across the regional and volume spectrum have adopted a portfolio of manufacturing concepts derived from both mass and lean production paradigms [1]. Globalization is a social and economic factor boosting the innovation process and the market pull instruments [2]. One of the main objectives for industries is to enrich their value proposition and ensure that it is fully perceived by the customer. This involves a large number of product variants and the need to make processes increasingly flexible. To pursue their goal, besides trying to maximize efficiency and optimize the process productivity by reducing waste and loss, enterprises cannot disregard strategies of sustainability and safety that encompass all workers involved in the process. 
The manufacturing industry has to move from mass production to mass customization, which stands for offering a high quantity of goods that are different from each other and customized for the single consumer [3]. This new paradigm crashes with current assembly systems because now they are not able to follow the market requirements; it is thus necessary to introduce new technologies to make them more agile and responsive. Future plants should give more flexibility to the whole production or assembly lines, both for the system design and used equipment [4]. Factories all over the world are approaching a transformation with consequences both in technical and social fields; in this transition, human has still a central role [5].

Companies are implementing lean philosophies to streamline production systems, using the least possible resources still ensuring product quality, to protect their competitiveness in the actual market.

One of the best-established methodologies is the World Class Manufacturing (WCM) approach that can be summarized as a set of principles, standards, and techniques for managing the operational process of a company [6]. WCM proposes itself as a roadmap to reach, step by step, a zero-waste state, implementing little improvements each time (continuous improvement), applying standard methodologies, and actively including employees, no matter what their role is Sandeep and Panwar [7]. WCM actively engages all personnel in the continuous-improvement process; every action undertaken in this direction aims at increasing their satisfaction and the quality of their workplaces [8].

How widely accepted methodologies can stand the advent of new technologies, innovative communication channels, and workplaces organization? The challenge is to embrace the changes introduced by the fourth industrial revolution as opportunities to support the role of the human operator from a physical and cognitive point of view, since the analysis of anthropocentric perspectives [9], and let innovative technologies and existing methodologies to smoothly adjust each other. With Industry 4.0 (also known as I4.0), design methodologies will have to combine methods, share goals, and adapt tools to the new industrial paradigm.

In the factory of the future, human will continue to be the principal actor of continuous improvement and the real added value to be competitive in the marketplace. From this, it arises the need for industries to necessarily deal with human sustainability and be committed to the humancentered manufacturing approach that aims at improving workers' capability, health, and safety [10]. Guaranteeing health, safety, and well-being to workers has a positive impact on the overall industrial system. Efficiency, productivity, and product quality strictly depend on human performance (e.g., perceived comfort, physical and mental workload, simplicity of actions, personal satisfaction). The whole industry gains benefit from included, motivated, and satisfied employees [11].

In this context, the present work focuses on designing work equipment from a human-centered perspective starting from the root cause analysis of a problem. Existing approaches rarely support the qualitative and quantitative definition of the problem or include the solution validation by an objective ergonomics analysis. This paper aims to overcome this lack by proposing a structured methodology to support the identification and understanding of the problem toward the design of solutions able to support humans in the effective and efficient execution of their work while preserving their health and safety. The interaction design, which consists of the analysis and design of the interaction between the operator and the work equipment, is then a key aspect of the proposed methodology.

For each stage of the design process, the opportunities offered by the Key Enabling Technologies (KETs) of the Industry 4.0 are also investigated. For example, new data analysis techniques can simplify the root cause identification, Internet of Things (IoT) can enable objective evaluations of human well-being, advanced tools can support the work execution from a physical and cognitive point of view, and the digital systems allow simulating the solution in a virtual environment and detecting problems in the early design stages.

The methodology should be well combined with the industrial environment that day by day has to deal with rapid market changes, high levels of customization, and the demand for products with a shorter life cycle; together with enterprise also the methodology must be increasingly flexible and follow industrial dynamics. Besides the wide variety of goods to be produced, standardization of operations is a key enabler of manufacturing flexibility; therefore, it should be included in the design requirements of a workstation [12]. Equipment design is because designers are required to find solutions that both concurrently increase performance and improve operators' well-being [13]. Although several studies focused on developing an innovative methodology to support the workstation design [14, 15], few works focused on the design of manufacturing equipment. This paper aims to address this issue by considering requirements, targets, and constraints related to ergonomic, technical, and economic aspects.

Section 2 reviews the background that leads to the rise of the methodology; papers concerning WCM and other methodologies have been analyzed, with regard to ones introduced in enterprises to improve production and management systems and focused on human factors and the Workplace Organization pillar. The section also explores works related to the introduction of objective and repeatable evaluation of as-is and improved working conditions through the use of KETs of the Industry 4.0 paradigm. Those revealed themselves to be useful in enhancement and 
preventing ergonomic issues from the design phase of a production process. However, Sect. 2 highlights the need to include I4.0 technologies in a comprehensive methodology that can be followed to design ergonomic workstations and equipment. This is the focus of the present paper. The next section, Sect. 3, introduces and explains the proposed methodology, highlighting its steps and goals, such as problem identification and quantification, the definition of targets, and requirements to be taken into account when drafting a suitable solution for a specific problem. Then, in Sect. 4, a case study is reported; it consists in the application of the methodology in a manufacturing company, a world leader in producing and commercializing agricultural and industrial vehicles, where WCM is a well-established methodology, and the industrial revolution is becoming reality. Section 5 shows the main outcomes of the present work, quantitatively assessing the impact of the ad-hoc designed equipment and comparing the as-is and to-be workstation. Section 6 critically reviews the work, and highlights both strengths and weaknesses of the presented methodology; it also encloses suggestions for future works.

\section{Research background}

The importance of ergonomic principles in work and workplace design and the benefits related to the adoption of human-centered approaches are amply argued in literature $[11,16]$. Working in an unhealthy environment negatively influences workers' well-being; this can affect the way they complete their tasks. Moreover, performing repetitive tasks and assuming uncomfortable postures can be correlated to the insurgence of work-related musculoskeletal disorders (MSDs) [17].

Integrate ergonomics and human factors at each stage of the design process of work-related items is convenient both for humans and the company. This enhances workers' physical and psychosocial conditions and favors the increase in productivity and quality of products [18]. Therefore, the design of the workstation and its included tools and equipment has to be focused on reducing and mitigating workers' risks and mental demand [19]. However, ergonomic aspects are often neglected in the design phase, and corrective actions are applied only during the production phase when intervention costs are higher [20]. Although literature proved that ergonomics has both social and economic benefits, the investigation of the possible risks in the design phase is still not common [21]. To demonstrate the strict relation between ergonomics and costs, Falck and Rosenquist developed a model for the calculation of the costs of poor ergonomics of the assembly line design [22]. Engineers and ergonomists should work together during the design phase and the model could help them assess ergonomic conditions by relating these with quality and productivity index.

Several papers illustrate the relevance of combining the design of assembly lines and ergonomics. Battini et al. proposed a concurrent engineering approach for improving assembly system design considering ergonomic aspects [14]. Djapan et al. described an innovative methodology for risk assessment concerning human, organizational, and technical/technological factors and proposed a tool for the manufacturing sector to increase workplace safety [23]. A protocol analysis for supporting workstation design is proposed by Peruzzini et al., who consider both physical and cognitive ergonomics and explore different digital set-up [24]. The existing literature mainly focuses on developing a comprehensive methodology to design workstations considering ergonomic aspects even during the design phase, but for the equipment design, human factors are often neglected. This paper deals with this open issue and presents a complete methodology to support the design of manufacturing equipment considering human factors.

Widely known methodologies, such as Total Productive Maintenance (TPM), Total Quality Management (TQM), and WCM, based on Lean Manufacturing Philosophy, have been developed and introduced in enterprises to improve production and management systems, including all pillars of sustainability [25]. Brito et al. pointed out that implement Lean Manufacturing methodologies, without considering human factors, does not necessarily bring benefits to industries [26]. Through WCM nowadays the most important goods producers and services providers certify their processes and guarantee control and reduction over production costs systematically applying objective and repeatable methodologies. Naranje et al. applied the WCM method in the Quality pillar to reduce defects in the tea packing process [27]. Alonso et al. presented a correlation between Environment and Logistics pillars proving that the application of proactive actions on the Logistics pillar can also enhance the Environment pillar [28]. De Felice and Petrillo proposed a methodological approach for the Logistics pillar in the automotive industry to improve the work standards by following the WCM approach [29]. Although several studies on WCM exist, few of them focus on human factors [25]. There is still a lack of formal and comprehensive approaches of WCM that considers, preserves, and enriches the value of man. The main contribution of this paper is a methodology focusing on the Workplace Organization pillar that collects and systematizes existing methods and tools to design ergonomic equipment.

The fourth industrial revolution brings to light innovative solutions and challenges; new tools and methodological approaches must be developed to cope with the new industrial scenario. This provides much more opportunities to support the human operator from a physical and cognitive point 
of view since the analysis of anthropocentric perspectives within Industry 4.0 highlights how the digital transformation in the manufacturing production system is changing his role [9]. In this scenario, operator 4.0 is defined as a smart and skilled operator who synergically cooperates with advanced human-machine interaction technologies towards achieving human-automation symbiosis systems [30]. He can be supported by new enabling technologies and enhance his skills and capabilities by performing more value-added activities without mental and physical stress [31, 32]. In this context, digital human models (DHM) represent a proactive tool that allows rapid virtual prototype development [33]. Digital manufacturing is one of the main enabling technologies of Industry 4.0 and it allows time reduction for a product or process design. Considering the need for evaluating ergonomic aspects at the early design phase, digital systems provide the possibility to simulate the developed workplace in a virtual environment and to reproduce manual assembly activities to identify possible risks. In this way, the identified risks can be immediately mitigated before realizing the physical prototype with low times and costs. In this regard, Caputo et al. presented a framework that uses digital twins of workstations to reduce the time used to design an assembly line [15]. Alkan et al. developed a software solution based on the digital human model that uses operator position and workload data for virtual manufacturing process planning [34]. Digital systems and Virtual Reality are effective tools to evaluate the interaction between the worker and the workplace relating to ergonomic aspects. Azizi et al. used virtual reality to develop a comprehensive approach for the assessment of a manufacturing cell considering ergonomic principles [19]. Di Gironimo and Patalano presented the re-design of a railway locomotive in a virtual environment following ergonomic requirements [35]. The ergonomic analysis can be performed both in a virtual environment and a real environment with the physical prototype. Data collected from the simulation can be confirmed and validated by the use of a motion capture system when the physical prototype is created and tested $[36,37]$. The key factor of the abovementioned studies is the assessment of ergonomic aspects since the early design phase. In this paper, ergonomic aspects are considered in each step of the proposed methodology and their assessment is supported by I4.0 technologies.

Industry 4.0 and WCM approaches are based on different principles. The Industry 4.0 paradigm allows the transformation of a factory into a smart, interconnected, and flexible environment. WCM is a structured methodology based on continuous improvement and the complete elimination of waste. However, it is possible to identify some synergic correlations between the Industry 4.0 principles and WCM elements. Ebrahimi et al. investigated the possibility of merging these two approaches, they demonstrated that several elements of Industry 4.0 could support the evolution of WCM technical pillars [6]. D'Orazio et al. analyzed the possible synergies between I4.0 and WCM and they proposed a matrix in which are defined all the technologies that can be used in the WCM methodology [38]. They observed that I4.0 technologies can enhance the WCM program in terms of greater data accuracy, precision, and reliability. Regarding the Workplace Organization pillar, they confirmed that technologies can significantly improve ergonomics allowing the analysis of the risks at the early stage of design. Although these studies analyze the correlation between WCM and I4.0, the open issue is to include I4.0 technologies in a comprehensive methodology that can be followed to design ergonomic workstations and equipment. In this context, the proposed solution tries to merge I4.0 technologies and WCM standards into a structured methodology to support the design of manufacturing equipment considering different drivers such as human factors, productivity, and quality.

\subsection{Applied WCM methods and tools}

Table 1 summarizes the description of all the WCM methods and tools used in the proposed methodology. The fundamental principle of WCM is reducing loss and wastes through the application of standard methods and tools with the involvement of all the company employees.

\section{Methodology}

The proposed methodology aims to support the design of manufacturing equipment able to improve ergonomics, efficiency, and standardization of a workstation. As shown in Fig. 1, it is composed of seven main steps, which can be strengthened by the enabling technologies of Industry 4.0.

The first step is to identify, describe, and document the problem. Collecting, combining, and sharing information with stakeholders (e.g., horizontal, and vertical integration at the production and operational level) can offer some insight into the problem. Considering different data sources (e.g., industrial internet of things) and data analytics techniques can lead to a clearer definition and understanding of the problem and its causes.

The second step involves gaining a deeper comprehension of the problem to identify its exact nature. Qualitative results coming from Step 1 need to be checked and quantified. It is also a good opportunity to look at the relationships between the key elements of the problem. Data play again a key role.

Once an initial working definition and structure of the problem have been identified, it is easier to identify and understand the gap between the current situation and the desired one. It is the basis of Step 3, which aims to set targets considering technical and economic constraints, regulatory requirements, and best practices. In this phase, particular 
Table 1 Applied WCM methods and tools description [39]

\begin{tabular}{|c|c|}
\hline Methods and tools & Description \\
\hline $5 \mathrm{G}$ & $\begin{array}{l}\text { It is a methodology for the description and the analysis of } \\
\text { a loss phenomenon (defects, failures, breakdowns, } \\
\text { malfunctions, non-value-added activities, etc.). It is } \\
\text { based on the facts and the use of the five senses }\end{array}$ \\
\hline $5 \mathrm{~W}+1 \mathrm{H}$ & $\begin{array}{l}\text { It is used to ensure a complete analysis of a problem on } \\
\text { all its fundamental aspects. It supports the collection of } \\
\text { all the data for solving the problem. The questions } \\
\text { corresponding to the } 5 \mathrm{~W} \text { and } 1 \mathrm{H} \text { are: Who? What? } \\
\text { Why? Where? When? How? }\end{array}$ \\
\hline $4 M+1 D$ & $\begin{array}{l}\text { It is used to analyze a phenomenon by identifying the list } \\
\text { of possible factors (causes, sub-causes) that give rise to } \\
\text { the phenomenon. For the } 4 \mathrm{M}+1 \mathrm{D} \text { the causes are } \\
\text { grouped into } 5 \text { categories: Methods; Materials; } \\
\text { Machines; Man; Design }\end{array}$ \\
\hline 5 whys & $\begin{array}{l}\text { It is a tool aimed at searching for causes and possible } \\
\text { solutions through a consecutive series of whys }\end{array}$ \\
\hline TWTTP (The Way To Teach People) & $\begin{array}{l}\text { It is an interview with the operator to understand his level } \\
\text { of knowledge of the product, process, and equipment he } \\
\text { uses }\end{array}$ \\
\hline HERCA (Human Error Root Cause Analysis) & $\begin{array}{l}\text { it is an interview with the operator to understand if there } \\
\text { are any issues related to the design of } \\
\text { process/procedures, technical issues, workstations, the } \\
\text { behavior of the operator himself, and his distractions or } \\
\text { forgetfulness }\end{array}$ \\
\hline MURI & $\begin{array}{l}\text { It is an ergonomic analysis of the operator to identify } \\
\text { activities that involve risky and unnatural postures, } \\
\text { movements, and positions }\end{array}$ \\
\hline MURA & $\begin{array}{l}\text { It is an analysis useful to identify irregular movements } \\
\text { and operations that involve a variability of the time } \\
\text { required to perform the operations }\end{array}$ \\
\hline MUDA & $\begin{array}{l}\text { It is an analysis of all those activities performed by the } \\
\text { operator which do not add value to the product and } \\
\text { must be eliminated or reduced }\end{array}$ \\
\hline Spaghetti chart & $\begin{array}{l}\text { It is a graphical tool used to visualize and quantify the } \\
\text { paths and the steps performed by operators during the } \\
\text { activities }\end{array}$ \\
\hline Golden and strike zone & $\begin{array}{l}\text { Analysis of work operations in the area that favors the } \\
\text { handling in order to minimize movement to reduce } \\
\text { fatigue and ergonomic risks }\end{array}$ \\
\hline
\end{tabular}

attention is also paid to the human equipment interaction. New driving forces (e.g., speeding up the time to market), challenges (e.g., digitalization), and regulations (e.g., human-robot collaboration) should be faced by industries in the wake of the industry 4.0 transition.

In Step 4, respecting the constraints, the teamwork has to find possible solutions by brainstorming techniques and degressive methods. A critical review of existing industry 4.0 applications could enhance teamwork knowledge. Once a possible solution is found, it is developed and engineered in steps 5 and 6 . The former is virtual prototyping with the creation of the equipment's CAD model that is necessary to conduct structural, functional, and ergonomic analysis. These simulations could reveal some weaknesses of the equipment design, which can be iteratively modified to respect all technical and functional constraints. Digital twin and simulation based on extended reality technologies are effective tools to be used in Step 5. After the validation of the virtual prototype, Step 6 is based on building the physical prototype, used for testing the equipment in the workstation. During this process, it is possible to optimize iteratively some features of the equipment. In this regard, several opportunities arise from emerging technologies such as additive manufacturing (which reduces design cycles and speeds up prototyping, review, and approval times), advanced manufacturing solutions (e.g., exoskeleton, cobots that physically support the operators), and the extended reality (as a cognitive and sensorial aid for workers).

Step 7 allows analyzing the benefits after the implementation of the prototype in the workstation. It consists of 


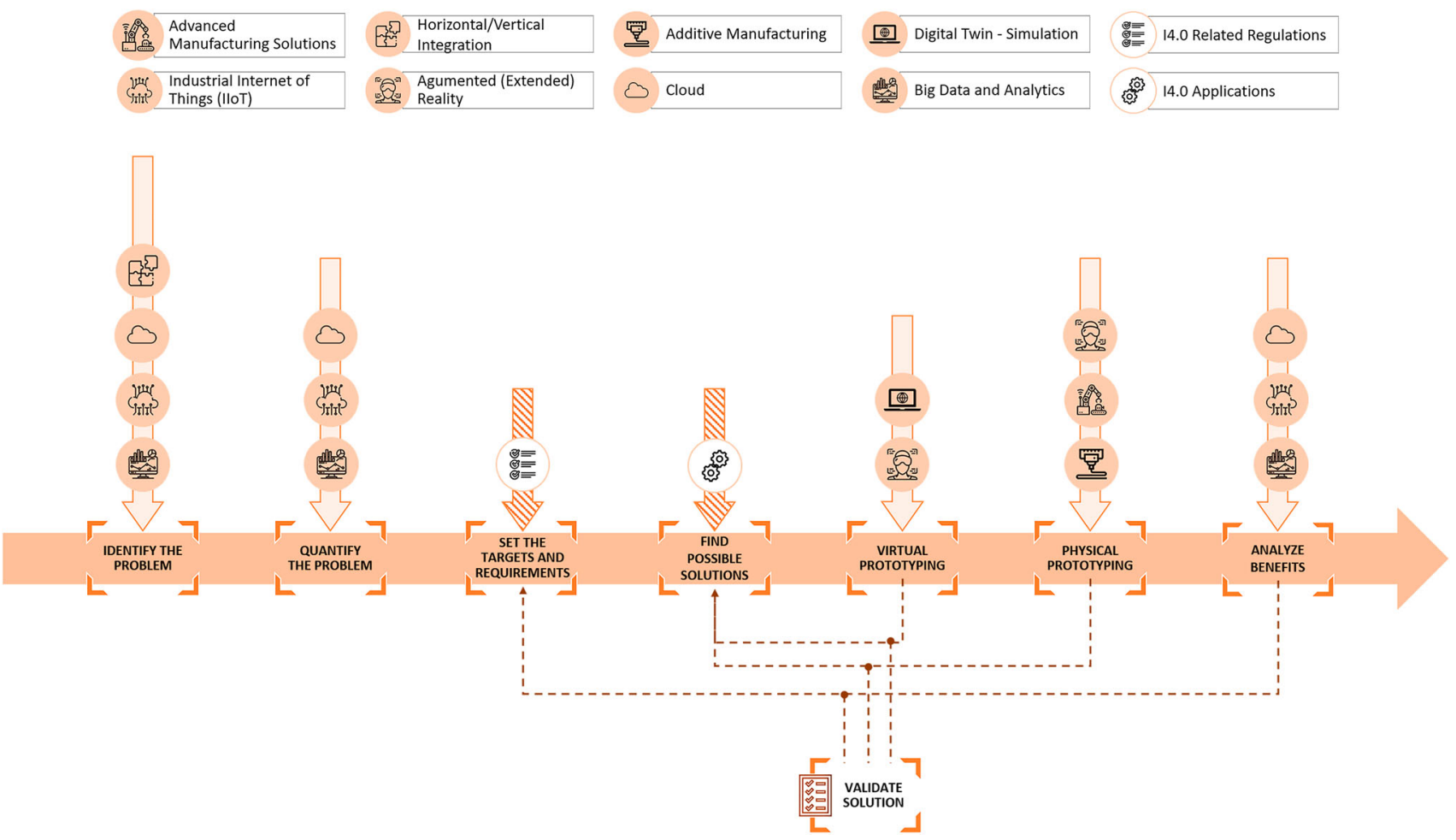

Fig. 1 Methodology for human-centered design of ergonomic manufacturing equipment

calculating key performance indicators (including the benefit/cost ratio), exploiting the same analysis methods and tools of step 2, and comparing the results with those of the "as-is" workstation. If satisfactory results are achieved, the solution can be validated, and possibly replicated, otherwise the unsatisfied requirements must be analyzed and reviewed.

The validation of the solution implies that all the constraints defined in step 3 have been respected and all the fixed targets have been achieved. Otherwise, it is appropriate to investigate the extent and cause of the deviation from the desired objectives to lead the redesign. In this regard, a classification of requirements (e.g., mandatory, desirable, optional) or the definition of tolerance ranges could streamline the review process.

The following paragraphs focus on the first three steps of the methodology to describe in more detail how to carry out the problem analysis to then lead the design process. Indeed, this phase is often overlooked or taken for granted in the approaches proposed by the literature. Sometimes it is justified in the existence of different tools, however, a structured method for their use is necessary.

\subsection{Problem identification}

The problem identification is a crucial step that aims to identify the root cause of a problem by collecting and analyzing data. If the objective of this phase is clear, the systematic approach to be followed to achieve it is lacking. Therefore, the workflow shown in Fig. 2 is proposed. It effectively involves different stakeholders, methods, and tools. Firstly, the $5 \mathrm{G}$ tool, which is based on five senses, allows establishing the focus of the analysis. It means diagnosing the situation to focus on the real problem and not on its symptoms. The analysis has to start from the place where the events occur (gemba) taking benefits from the direct observations of all processes (gembutsu). The collection of facts (defects, failures, breakdowns, etc.) and data such as statistics, errors, frequencies, etc. (genjitsu) allows their comparison with desiderated and theoretical ones (genri). Company standards have to be investigated (gensoku) to set the analysis domain.

At this point, the observed phenomenon needs to be characterized. This step consists of describing how the problem occurs, how serious it is, and its outcomes and impacts. It also allows identifying any gaps in the gathered data. For this aim, a set of questions $(5 \mathrm{~W}+1 \mathrm{H})$ can be usefully employed:

- What is happening?

- When is it happening?

- Where is it happening?

- Which is involved?

- Who is involved?

- How is it manifesting? 
Fig. 2 Problem identification workflow

\section{$5 G$}

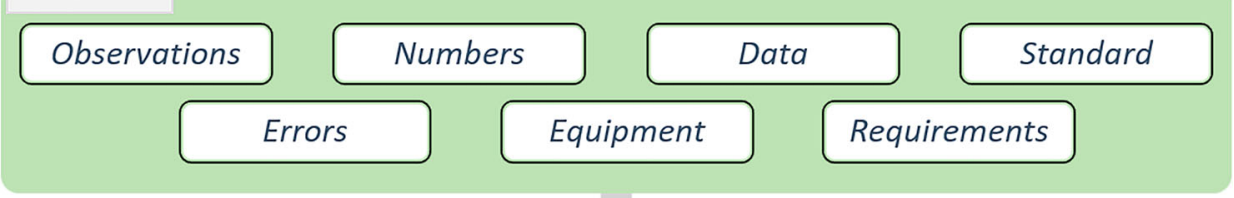

\section{FOCUS}

\begin{tabular}{|c|c|c|c|c|c|}
\hline $\begin{array}{l}\text { - Problem } \\
\text { - Error } \\
\text { - Defect }\end{array}$ & $\begin{array}{l}\text { - Frequency } \\
\text { - Random/ } \\
\text { Recurring } \\
\text {-Production } \\
\text { - Quality control }\end{array}$ & $\begin{array}{l}\text { - Line } \\
\text {-Workstation } \\
\text { - Component } \\
\text { - Product } \\
\text { - Machine }\end{array}$ & $\begin{array}{l}\text {-Product model } \\
\text { - Tendency/ } \\
\text { Inclination } \\
\text {-Trend }\end{array}$ & $\begin{array}{l}\text {-Operator } \\
\text {-Workshift } \\
\text { - Required skills }\end{array}$ & $\begin{array}{l}\text {-Problem } \\
\text { evidence } \\
\text { (manifestation) }\end{array}$ \\
\hline What & When & Where & Which & Who & How \\
\hline
\end{tabular}

\section{PHENOMENON}

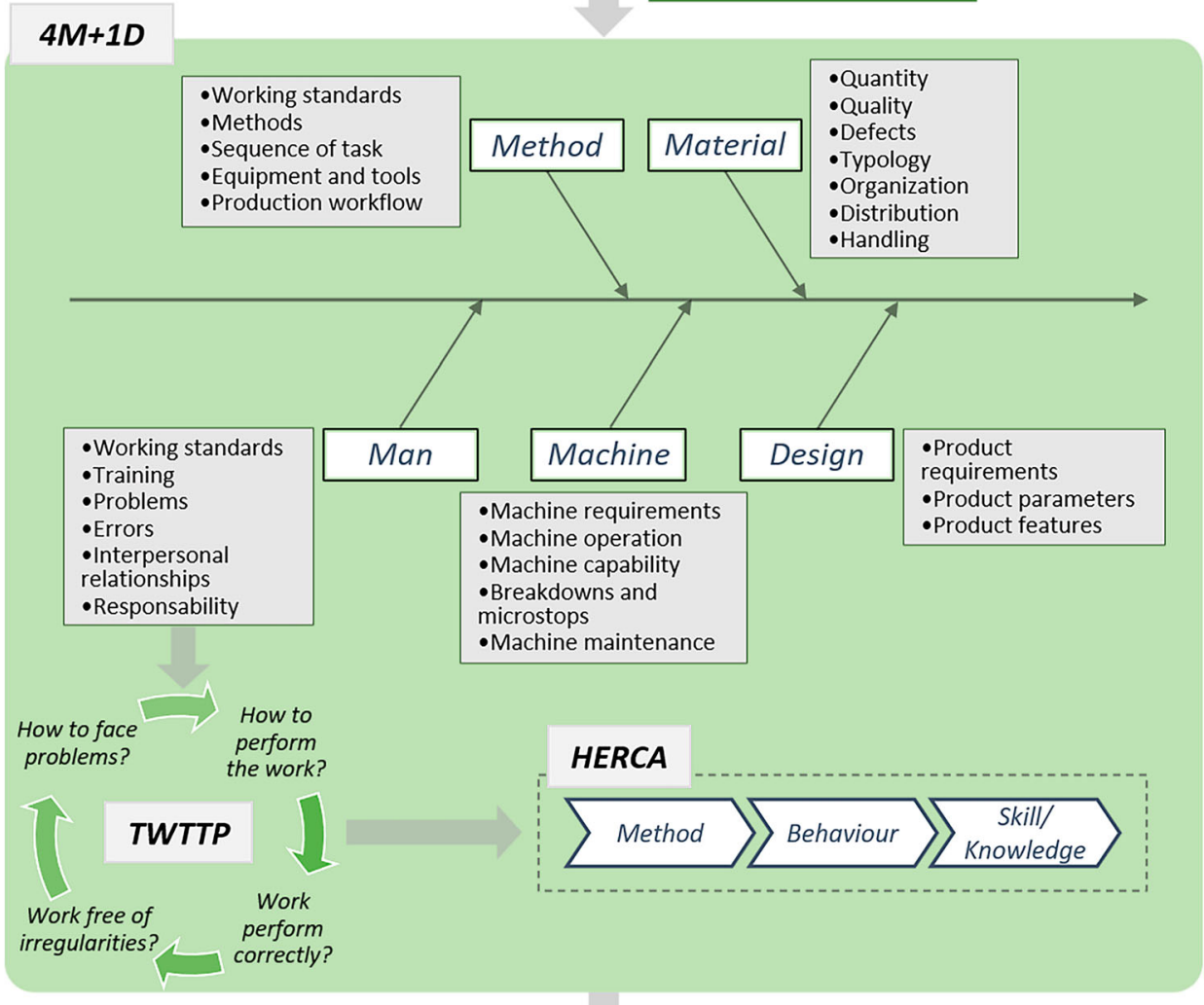

\section{CAUSES}

\section{WHYS}

Why

Why

Why

Why

Why

\section{ROOT CAUSES}


The involvement of all people closely affected by or concerned with the phenomenon is essential to make all team members aware of the existence of a problem and ensure their active participation in solving it.

In the following step, the true underlying problem has to be explored in more detail. Then, $4 \mathrm{M}+1 \mathrm{D}$, which is a cause-and-effect diagram, is used to identify possible factors (causes, sub-causes) that give rise to the phenomenon. $4 \mathrm{M}$ includes the following four key factors: method, material, machine, and man. The fifth category of cause (1D) is related to product design. In Fig. 2, for each category, a list of aspects to investigate is proposed. For each of them it is necessary to answer the following question: Can it be the cause of the phenomenon? According to the goal of the paper, the man category is further investigated by two tools: The way to teach people (TWTTP) and human error root cause analysis (HERCA). The former is an interview, based on 4 questions, to test the operator's training to perform a task and the level of process standardization. If no gaps emerge from TWTTP, the HERCA looks for other possible causes of the event of interest (human error, accident, etc.) that are not related to the operator's knowledge.

Each cause is then analyzed through a consecutive series of questions (5 whys). Framing the problem causes accurately makes stakeholders able to see which intervention strategies are most appropriate to tackle the problem and solve the root causes.

\subsection{Problem quantification}

The root causes emerged from the previous step are assigned to specific categories (i.e., product, tool, procedure, work, production, and layout). A set of analyses, aimed at quantifying the root causes, is enabled according to the defined categories. Figure 3 shows the main correlations between the root causes categories and the WCM tools.

In particular, the following five tools are used:

- MURI analysis that consists of identifying overburden, excessiveness, and unreasonableness. It aims to eliminate difficult and unnatural operations by defining standard movements that allow minimizing perceived effort, increasing productivity, and reducing human errors.

- MURA analysis that is used to identify unevenness, nonuniformity, and irregularity that implicate a high time variability. The final aim is to standardize the process.

- MUDA analysis, which aims to identify all non-valueadded activities, performed by the operator, that have to be eliminated or reduced (e.g., walking, packaging, waiting, hoisting, etc.).

- Spaghetti Chart, a tool used to trace all the movements that the operator performs to complete a work cycle by quantifying the number of steps taken. The aim is to optimize the workstation layout to minimize unnecessary movements and consequently reduce effort and increase productivity.

- Strike zone and Golden zone, which evaluate the working area from the ergonomic point of view. They classify the area in different risk zones according to the level of reachability of tools and equipment by the operator. The strike zone is the preferable area, when referring to the vertical plane, so that the worker performs the activities between his elbow and his shoulder. The golden zone is the preferable area so that the worker performs the activities between the visual field and the working height.

The tool category includes all the tools, devices, and equipment in the working area that support the operator in carrying out his work. Procedure refers to work instructions, standards, best-practices, etc. that allow the operator to correctly execute his work. In both cases, the $3 \mathrm{M}$ analysis is recommended. The MURI analysis can quantify the ergonomic risk for the operators related to the use of nonergonomic tool or work procedure; the MURA analysis can highlight the need to use a tool that ensures the operation repeatability levels, to standardize the tools used, or to define a standard for the execution of some operations; the MUDA analysis can quantify the percentage of non-valueadded activities that can be reduced through an appropriate tool or working method.

Work refers to all tasks that the operator has to execute. For example, inappropriate task management (e.g., sequence, dependency, priority) can generate a physical overburden (MURI), unwanted interruptions (MUDA), and non-optimized flows (Spaghetti Chart).

Product includes all characteristics of the product that can influence the process such as geometric characteristics, quality requirements, etc. For example, the former determines the quality of picking (MURI), the latter mainly involves the process repeatability (MURA).

All the data related to the production scheduling such as product variants, quantities, flows, etc. are included in the production category. In this case, the process balancing, product flows, and the operator's movements need to be evaluated.

Layout mainly refers to the working area organization in terms of space, storage, equipment, etc. It strictly influences the operator's movements, which can be evaluated by Spaghetti Chart and Strike zone and Golden zone tools.

\subsection{Targets and requirements definition}

To support the definition of design constraints and requirements the classification shown in Table 2 is proposed. Moreover, requirements can be classified according to a three-level priority scale to simplify the validation process: 


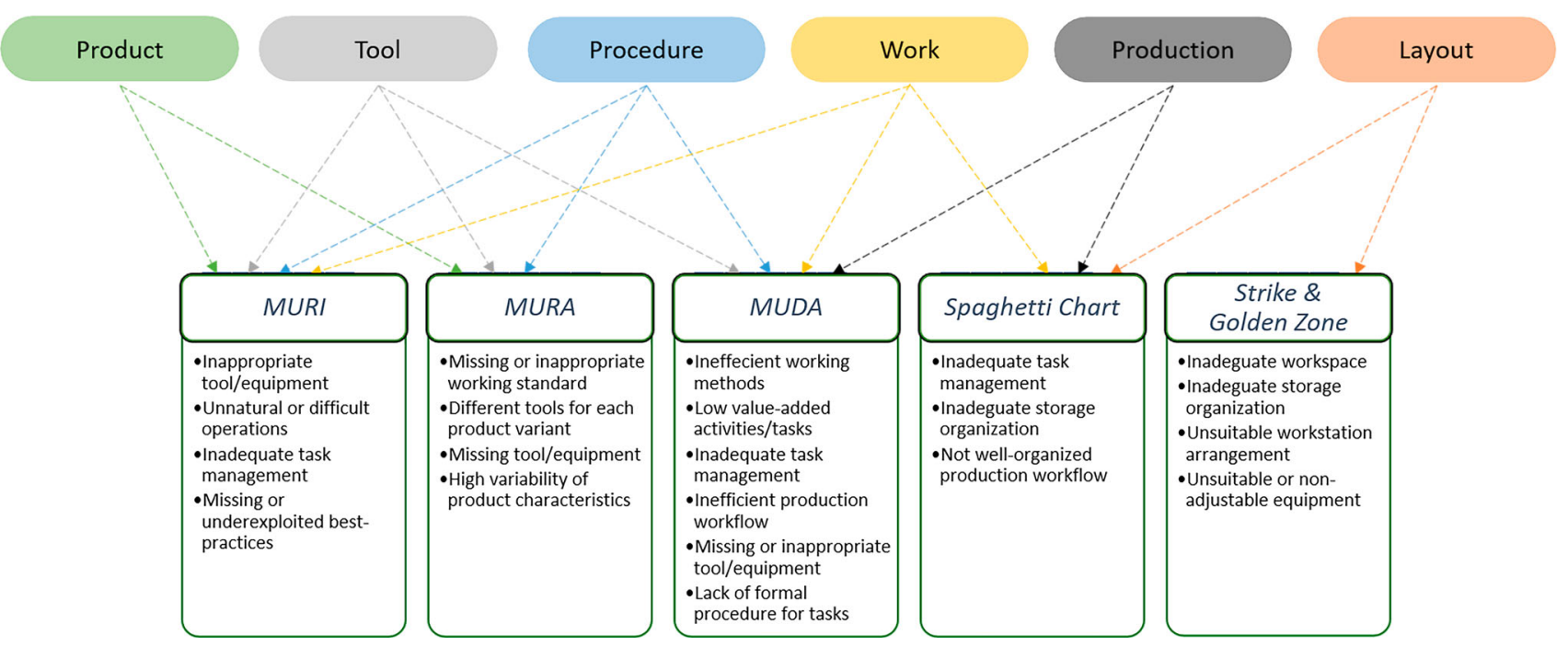

Fig. 3 Correlations between root causes categories and WCM tools

- 'Mandatory' requirements, which must be compulsorily respected (e.g., compliance to standards);

- 'Desirable' requirements, which are concrete opportunities to increase the company performance or workers well-being (e.g., negligible ergonomic risk instead of low risk);

- 'Optional' requirements, which, for example, allow the company to experiment with innovative solutions.

Finally, targets, which sometimes arise from constraints and requirements, can be set in absolute or relative terms. The former is more suitable when the objective to be achieved is clear and known a priori. The second usually arises from the evaluations carried out in the previous steps and consists of a percentage reduction or increase with respect to the "as-is" reference.

\section{Case study}

The method has been experimented in collaboration with a global manufacturer of agriculture and industrial vehicles that follows the WCM program. It requires the application of standard methods and tools and the involvement of people of different levels and departments. Production lines need to be extremely flexible; indeed, the repeatability index of the plant, which means the ratio between the number of tractors yearly manufactured and the number of different versions produced, is equal to 1,5 .

In this context, the case study involved the tractor assembly line and started in Gemba where it was possible to analyze people, products, and processes. The direct observation of work and flows allowed detecting an unplanned event: the involvement of a co-worker when performing a specific task of the tank assembly. At the same time, from the analysis of data provided by the company traceability system emerged that the tractor spent an extremely variable time in the same workstation. Often this time was even higher than desired. Another significant finding was the high frequency with which the hook of the hoist used to handle the tank was changed, which gave rise to significant set-up times. A more acceptable time distribution was observed for the other assembly workstations. Going into more detail of the tank assembly, no standard in the work execution was observed, however, the following main operations were identified: first, the operator uses the hoist to lift the tank after choosing the proper hook; the hoist is useful to place the tank next to the tractor and hold it while the operator links the electric cables and hydraulic pipes to the tractor; after that, the tank is permanently fixed to the tractor by screws and nuts and then the hoist is unfastened; in this last activities the operator sits on a chair provided with casters since the tractor is few centimeters above the floor. The outcome of the first step suggested focusing on the tank mounting process that concerned 9 tank typologies and 3 tractor models.

Filling out the $5 \mathrm{~W}+1 \mathrm{H}$ form allowed describing the observed phenomenon in-depth. In the analyzed workstation (where) the main problem referred to the high number of non-value-added (NVA) activities (what) that recurred each time the picking and the assembly of the tank were performed (when). All operators (who) spent too much time on activities such as walking, hoisting, waiting, etc. regardless of the product model (which), resulting in high variability of the assembly time (how).

The phenomenon was deeply analyzed by the cause-andeffect diagram $4 \mathrm{M}+1 \mathrm{D}$. The machine category has been neglected because the workstation is manual. Considering all the other categories, twelve different causes were hypoth- 
Table 2 Classification of constraints and requirements

\begin{tabular}{|c|c|}
\hline Constraints and requirements & Description and examples \\
\hline Technical aspects & $\begin{array}{l}\text { Information and features of the equipment related to the design, } \\
\text { fabrication/production process, and operation conditions (e.g., material, } \\
\text { weight, strength, etc.) }\end{array}$ \\
\hline Functional aspects & $\begin{array}{l}\text { Range of conditions to be satisfied in order not to negatively affect or } \\
\text { compromise the function or structure of the equipment (e.g., } \\
\text { mechanism, degrees of freedom, etc.) }\end{array}$ \\
\hline Spatial aspects & $\begin{array}{l}\text { Constraints related to the work area layout that aims to ensure the } \\
\text { accessibility, correct use, and maintenance of the equipment (e.g., } \\
\text { dimensions, size, etc.) }\end{array}$ \\
\hline Ergonomic aspects & $\begin{array}{l}\text { Constraints and requirements related to human factors (e.g., reachability, } \\
\text { visibility, etc.), which aim to provide the best human-equipment } \\
\text { interaction to protect the health and safety of workers }\end{array}$ \\
\hline Economic aspects & $\begin{array}{l}\text { All costs associated with the equipment life cycle and the benefits } \\
\text { originated from the equipment implementation in terms of performance, } \\
\text { cost-avoidance, etc. }\end{array}$ \\
\hline Normative aspects & $\begin{array}{l}\text { Compliance with laws, regulations, and standards, ensuring workers' } \\
\text { safety }\end{array}$ \\
\hline Company standards & $\begin{array}{l}\text { All the requirements coming from the company/sector knowledge, best } \\
\text { practices, protocols, procedures, and guidelines }\end{array}$ \\
\hline
\end{tabular}

esized. For example: for the man category, the operator may not know the working standards; for the material category, the tank could not be compliant; for the design category, the product requirements could not be respected; for the method category, a working standard may be lacking. After a further analysis the following three causes, belonging to the method category, have been selected: (i) hooks variety, (ii) the handling of bulky components, (iii) the need for a co-worker. In this case, since the identified causes are not related to the man category, this has not been further examined by TWTTP and HERCA.

By 5 Whys the following root causes were identified: (i) tractor models variety; (ii) the presence of several racks in the picking and mounting area; (iii) for a specific tractor model and a certain operation, the tank has to be held in a fixed and known position.

The next step was the quantification of the qualitative analysis results using typical tools of the Workplace Organization pillar.

The MURI analysis identified the picking of the hoist hook and the hooking of the tank to the hoist as critical operations (red score). The analysis showed that $18 \%$ of all operations presented high ergonomic risks (red score) and $15 \%$ medium risks (yellow score). The goal should be to eliminate all red scores; however, some operations cannot be completely changed due to some technological constraints (e.g., the low height of the tractor during the assembly), so the target is to reduce the red scores by at least $30 \%$.

In order to evaluate the working area from an ergonomic point of view the strike zone was carried out; since there is not any fixed workbench in the station, the golden zone could not be performed. The strike zone analysis detected some operations in the red zone (23\%); moreover, it was noticed that all these operations are related to the use of the hoist. For this reason, the target set is to achieve a zero red zone condition.

The MURA analysis confirmed high variability of the assembly time (standard deviation $=0.70$ ); this may be related not only to the wide range of tractors to be produced but also the lack of equipment suitable for all kinds of tanks. The goal is to standardize the process and the equipment to reduce both the standard time (cycle time) and the standard deviation.

The MUDA analysis allowed identifying NVA activities and divide them into different categories. The cycle time amounts to $3.21 \mathrm{~min}$ and the NVA activities (walking, hoisting, and handling) represent $48 \%$ of the total time. In particular, the operator performed 50 steps on average to complete the working cycle (Spaghetti Chart).

The output of the quantitative analysis provided a measure of the extent of waste and supported the definition of the targets for the design phase (Table 3). By critically analyzing the results multiple critical aspects related to the hoist emerged. For example, the qualitative analysis highlighted the lack of unique equipment suitable for all tanks; moreover, the ergonomic analysis revealed that many critical operations occurred when the hoist is used. For these reasons, the team agreed with the manufacturer on replacing the hoist with new equipment. It will be suitable to mount all different tanks and at the same time, it will not require other auxiliary tools to be used in assembly operations. This will ensure that the tank mounting workstation will not be the line bottleneck anymore, and the operator will take advantage of the equipment from an ergonomic point of view. 
Table 3 Target definition

\begin{tabular}{lll}
\hline Evaluation tool & Target (priority) & "As-is" reference \\
\hline MURI & $-30 \%$ red score (mandatory) & $18 \%$ red score \\
& Zero red score (desirable) & $15 \%$ yellow score \\
STRIKE ZONE & Zero red score (mandatory) & - \\
Borg CR10 & Borg score $<3$ (desirable) & - \\
MURA & $-50 \%$ standard deviation (desirable) & Standard time $=3.21$ \\
& & Standard deviation $=0.70$ \\
MUDA & $-20 \%$ NVA (desirable) & NVA $=48 \%$ \\
& & SVA $=11 \%$ \\
Cost-benefit analysis & B/C $>1$ (mandatory) & - \\
& B/C $>2$ (desirable) & \\
\hline
\end{tabular}

The design of the new equipment was even more challenging since, besides the target to achieve, also several constraints had to be considered. The main geometrical constraints were related to the height and width of the equipment; in particular, there were both a minimum height $(480 \mathrm{~mm})$ for mounting the tank and a maximum height $(780 \mathrm{~mm})$ and width $(470 \mathrm{~mm})$ to easily be inserted in the u-shaped rack. Moreover, the overall weight of the new equipment had to be as lower as possible, so the operator could effortlessly move it; in addition to this, other similar human interaction aspects were considered in equipment design such as posture, manual handling, usability, etc.

From a functional point of view, the main requirements to be met were the vertical motion, because the equipment had to smoothly move from the minimum to the maximum heights and a tilting motion for mounting tanks to specific tractor models.

Last but not least, safety measures had to be considered; since there are various shapes and dimensions of the tanks it is necessary to install a locking system, so the heavy tanks are fixed when are move in the workstation.

All the previous constraints had to be combined with the economic feasibility; the management established a limited budget for the realization of the equipment.

According to the stated requirements, the team identified a Low Cost Automation (LCA) as a feasible solution. The equipment design involved different skills, such as operators, pillar specialists, industrial methodists, R\&D, etc. who gathered in brainstorming sessions and came out with the equipment shown in Fig. 4 that succeeded in making the process more efficient and ergonomic.

LCA was versatile equipment that complied with all the requirements, built with onsite materials. It is a cart provided with casters manually pushed and pulled by the operator during the movements. The supporting structure of the LCA is a standard inside of the company: carts have already been used and validated in similar circumstances. Thanks to its modularity, it allowed the assembly of each type of tank, on all the tractor models assembled in the considered workstation with consequently benefits not only on timing but also from an economical point of view, since just one equipment was built.

The handle was designed to be ergonomic, and the height is adjustable to ensure a good posture for any operator during the tank repositioning. An electrical piston and four vertical rails ensure vertical motion. The wheels' design and the lightness of the structure aims to reduce the force that must be exerted by the operator to move the tank. To satisfy the weight constraint most parts of the structure are made of aluminum, except for some critical ones, made of steel to be more resistant. A specific blocking system was installed to prevent the plate from rotating, but it can be unhooked for the assembly of tanks that require tilting. Most of the tanks are provided with a metal plate on the bottom part; this component was used to fix the tank to the LCA by electric magnets installed on the plate of the LCA. In order to lock also tanks not provided with the metal plate, a tank grip system was designed. This can move forward and attach to the tank. All these features, showed in Fig. 4, allow all the tanks to be mounted to all kinds of tractors, using the same equipment.

The virtual prototype was carried out in CAD software and then the process was simulated in a virtual environment. The use of these I4.0 technologies (digital twin, simulation, and extended reality) allowed revealing problems and weaknesses of the equipment design. For this step Tecnomatix Process Simulate ${ }^{\circledR}$ (by Siemens) was used; it allowed evaluating and validating the functionality of the LCA, its usability, and the interaction with the operator. Figures $5 \mathrm{a}$ and $6 \mathrm{a}$ provide two examples of the virtual simulation of the mounting operation; the first shows the operator using the hoist (as-is), while the second one depicts the operator and the LCA (tobe). The software also allowed assessing the process from an ergonomic point of view. Results are shown later in Sect. 5, Table 4.

The virtual prototype was revealed to be extremely important because it allowed refining some features before the 


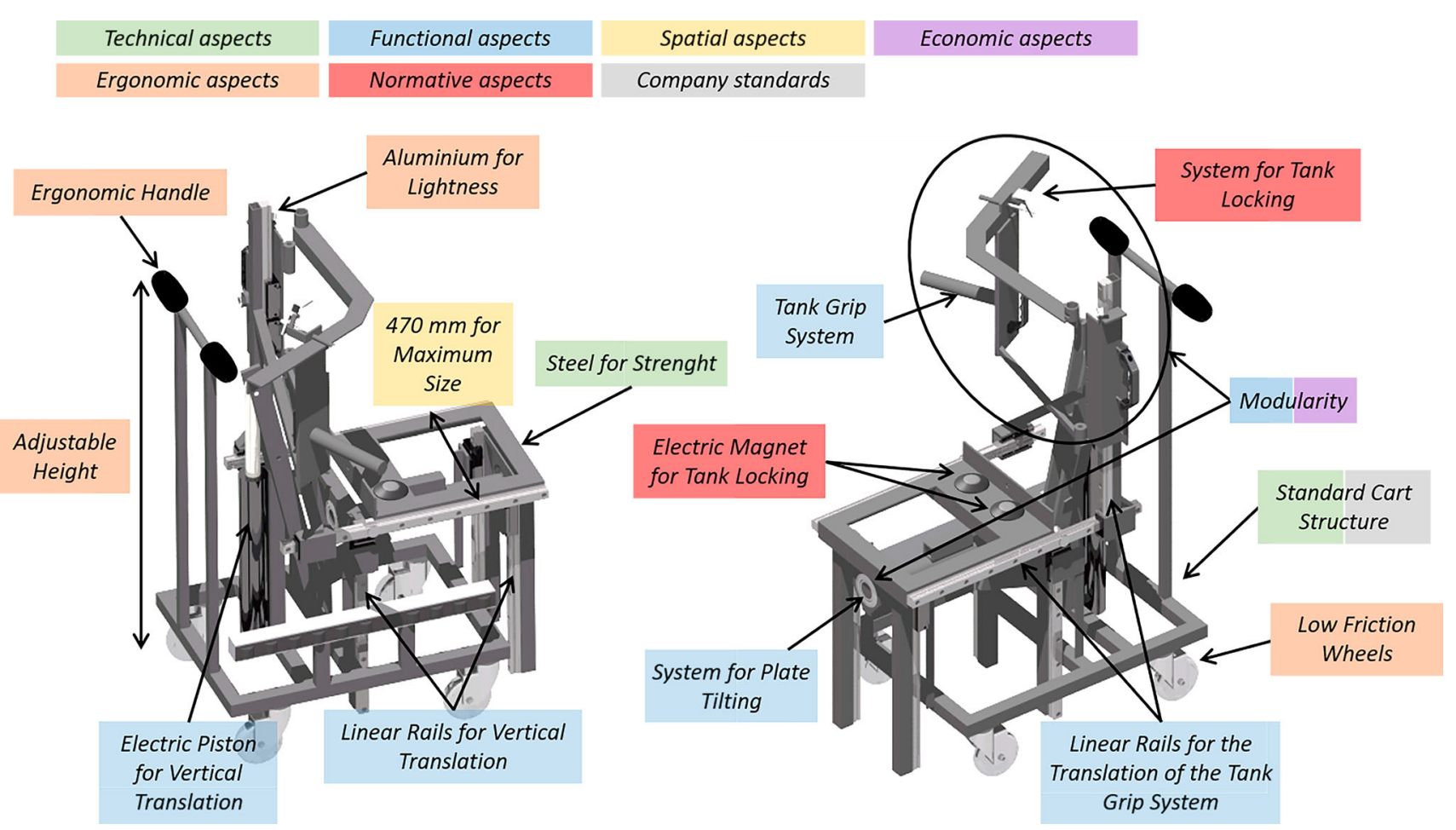

Fig. 4 Virtual prototype of LCA
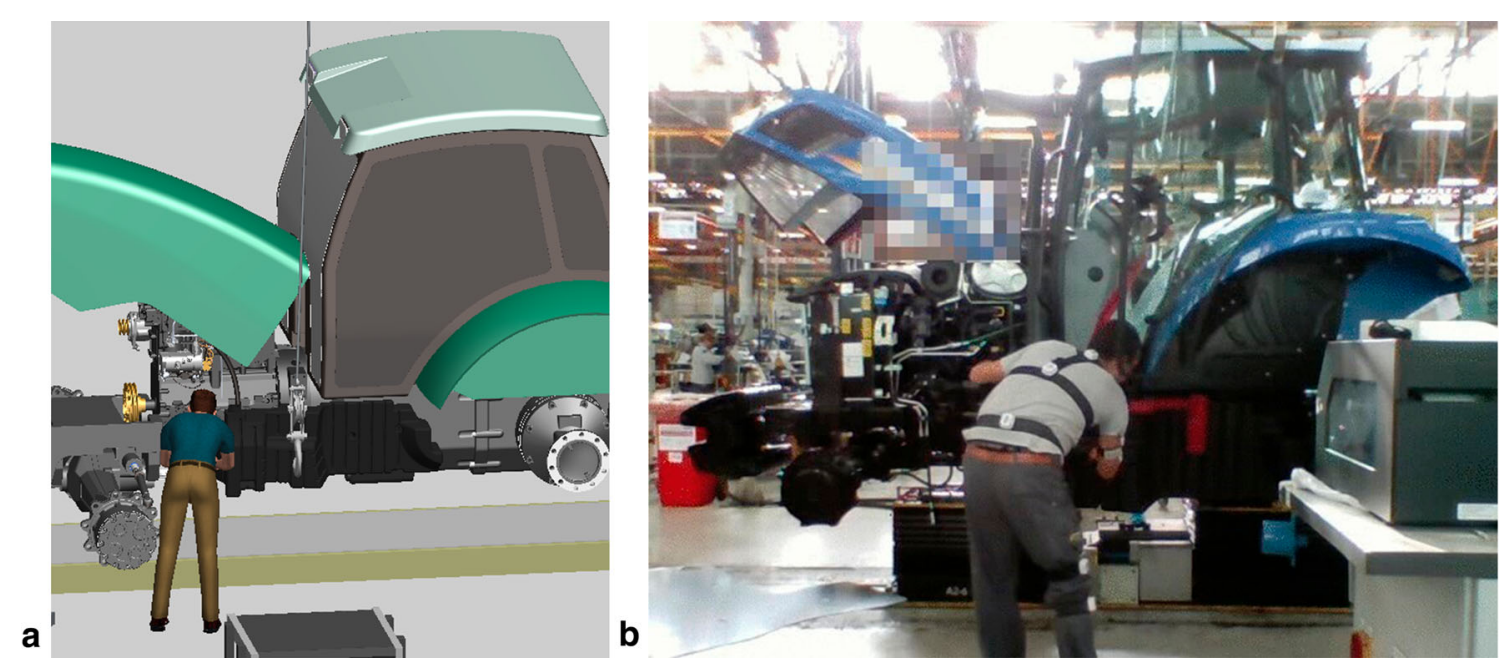

Fig. 5 Tank assembly with hoist (AS-IS): virtual simulation vs. real monitoring

equipment was built. Once validated the virtual model, the LCA was built internally at the company plant.

Finally, real experimentation was carried out by comparing the traditional assembly with that one supported by LCA. Expert-based evaluations (e.g., $3 \mathrm{M}$ analysis), IoT-based measures (Figs. 5b, 6b), and self-assessment techniques (Borg CR10 scale) were used. In particular, for the MURI analysis the Capitks Movit system G1 ${ }^{\circledR}$ was used for motion capture and posture recognition and the Myo Armand ${ }^{\circledR}$ for the measurement of the electrical activity of muscles and the extraction of significant features (e.g., root mean square) to evaluate the muscular effort. The use of IoT devices allowed assessing the ergonomic risks for the operator in an objective and accurate way.

\section{Results}

After the implementation of the prototype in the workstation, in step 7 quantitative analyses are carried out again. 

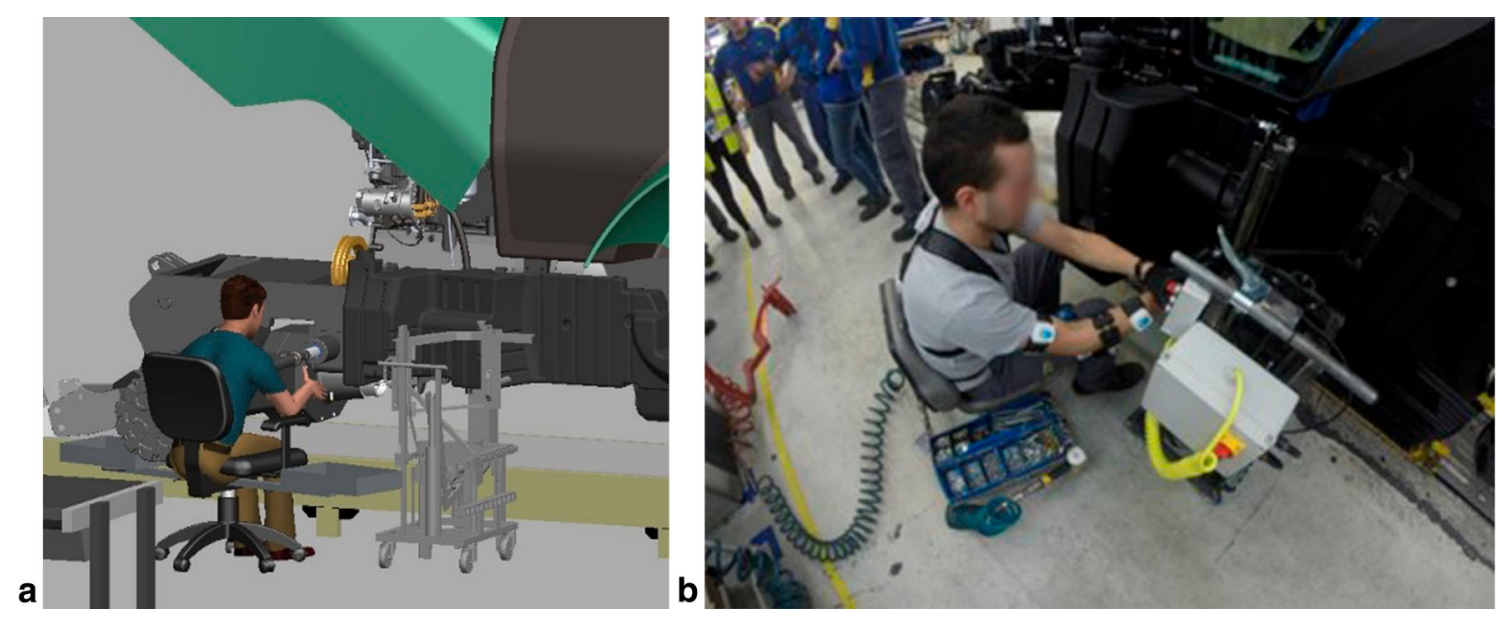

Fig. 6 Tank assembly with LCA (TO BE): virtual simulation vs. real monitoring

Table 4 Comparison between ergonomic analyses

\begin{tabular}{lllll}
\hline & & Low risk (\%) & Medium risk (\%) & High risk (\%) \\
\hline Simulation-based analysis & AS IS & 61 & 20 & 19 \\
& TO BE & 73 & 17 & 10 \\
\multirow{2}{*}{ Expert-based analysis } & AS IS & 76 & 18 & 6 \\
& TO BE & 87 & 11 & 2 \\
IoT-based analysis & AS IS & 71 & 16 & 13 \\
& TO BE & 82 & 10 & 8 \\
\hline
\end{tabular}

This allows comparing the results previously collected (As$i s$ ) with present scores (To-be) and thus assesses whether the expected goals have been achieved and to what extent. In this phase, constraints observance and fixed target achievement are checked. All to-be analyses were performed in the same conditions of as-is analysis. Overall, the LCA introduction in the assembly process allowed obtaining significant benefits both from productive and ergonomic points of view.

The replacement of the hoist with the LCA eliminated all spatial, temporal, and resources allocation constraints. The hoist represents a spatial obstacle because it commits the layout of the workstation and potential future changes. WCM provides several reasons for reducing the use of hoists: low flexibility, high NVA activities, high installation and maintenance costs, etc. On the other hand, the LCA can be easily moved and manipulated in any location on the shop floor. Moreover, by using the LCA the operator is able to autonomously mount every model of the tank, without having to rely on any co-worker.

By comparing the MURA analysis (Fig. 7), it can be noticed that the Gaussian function shrank and moved towards the ordinate axis: the former represents the reduction of process variability (standard deviation), the latter the decrease of the standard time. As shown in Fig. 7, the MURA reduction and the standard time reduction are equal to $68,7 \%$ and $9,4 \%$ respectively. One of the greatest benefits of standard- ization relies on the possibility to succeed without errors in tank mounting operations also for not expert workers.

Figure 8 shows the comparison between As-is and To-be situations according to the MUDA analysis. The introduction of the LCA decreased NVA by $28 \%$; all red scores, related to the hoist, were eliminated and the walking halved, although evidence indicated an increase in handling that encompassed all operations intended to move the LCA. The considerable reduction of steps was confirmed by the Spaghetti chart: after introducing the LCA they are $48,9 \%$ less than before. It is due to the process standardization, which entails a stable working cycle that does not vary according to the mounted tank model.

As suggested by the methodology, the team compared the benefits of the new equipment to the related costs in order to validate and possibly replicate the LCA. The main benefits originated from the reduction of the standard time, NVA activities, and maintenance costs (hoist replacement). On the other hand, the cost items referred to labor cost (project design, development, and production), materials, and LCA production (processes). The benefit/cost ratio resulted equal to 2, so the Cost Deployment pillar approved the project.

From the ergonomic point of view, all targets have been successfully achieved. The LCA allowed the operator to perform all tasks in the strike zone, which not only meant less effort and better posture but also greater efficiency. 
Fig. 7 Results of MURA analysis

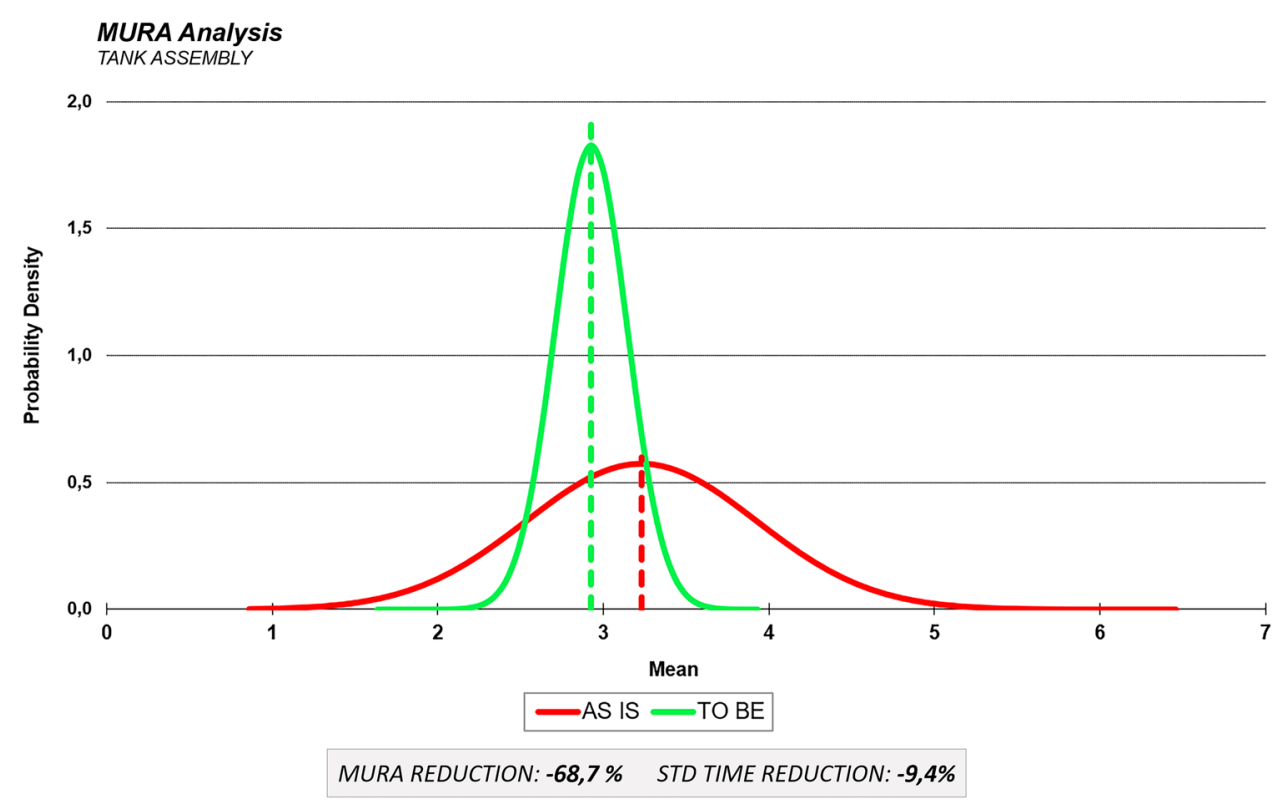

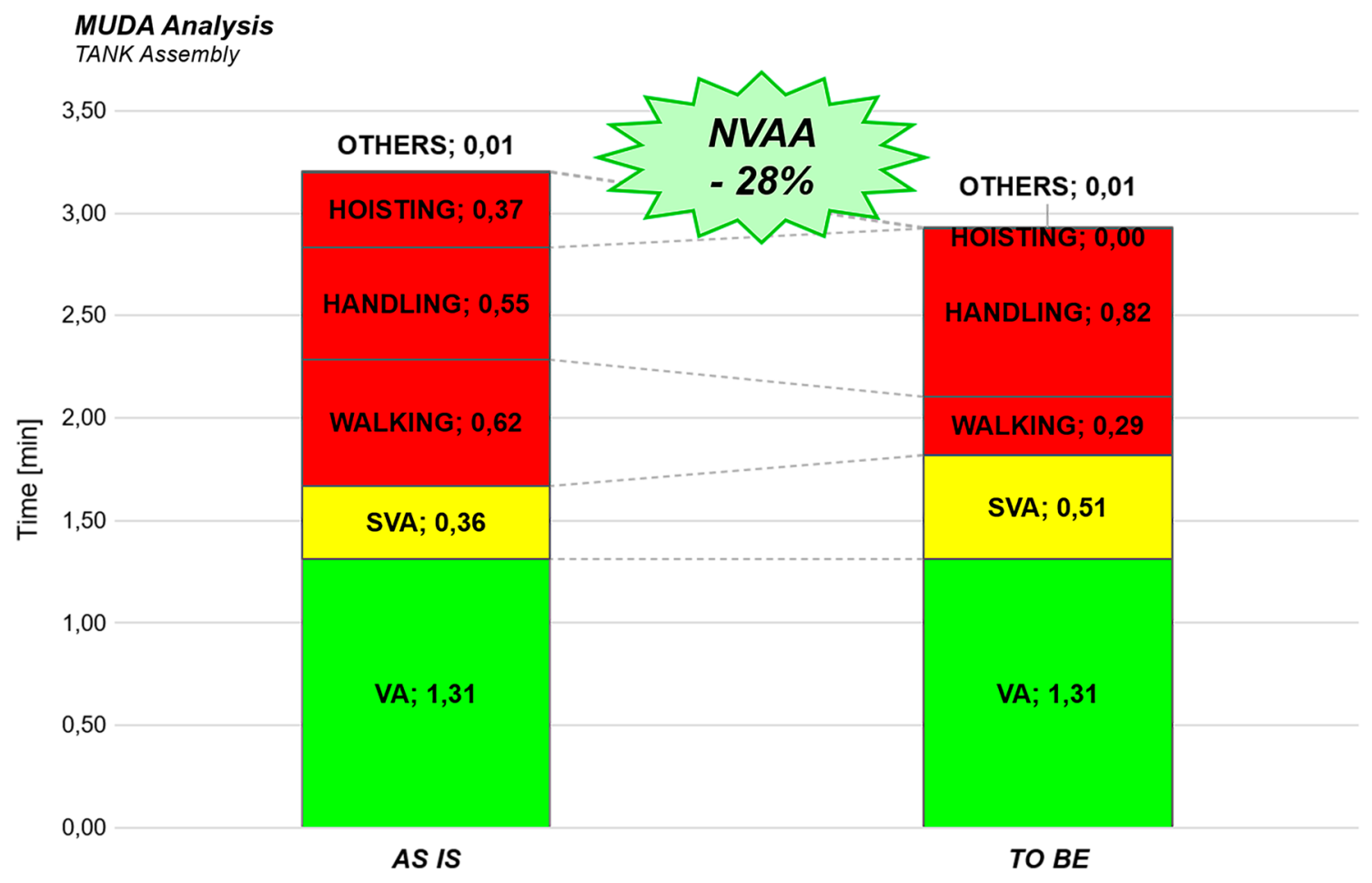

Fig. 8 Results of MUDA Analysis

To get a complete overview of the ergonomic profile of the new workstation, the MURI analysis was performed, in a subjective (expert-based) and objective (based on data collected through the Capitks Movit system G1®) way, and the muscular effort was evaluated by monitoring the EMG signal. Both analyses highlighted the benefits introduced with LCA. As shown in Fig. 9, the high risk of overburdening (red score) had been almost halved, and the medium risk (yellow score) had been reduced by $33 \%$ with positive effects on workers' health. Moreover, the reduction of the root mean square values of the EMG signal (from 0.1333 to 0.1307) demonstrated a lower muscular effort required by the new equipment compared to the previous one, which was confirmed by the operator's perceived exertion (Borg CR10 from 2.5 to 2 ).

Table 4 summarizes results, both for As-is and To-be situations, of traditional and innovative methods. The expertbased analysis results to be more general and affected by 

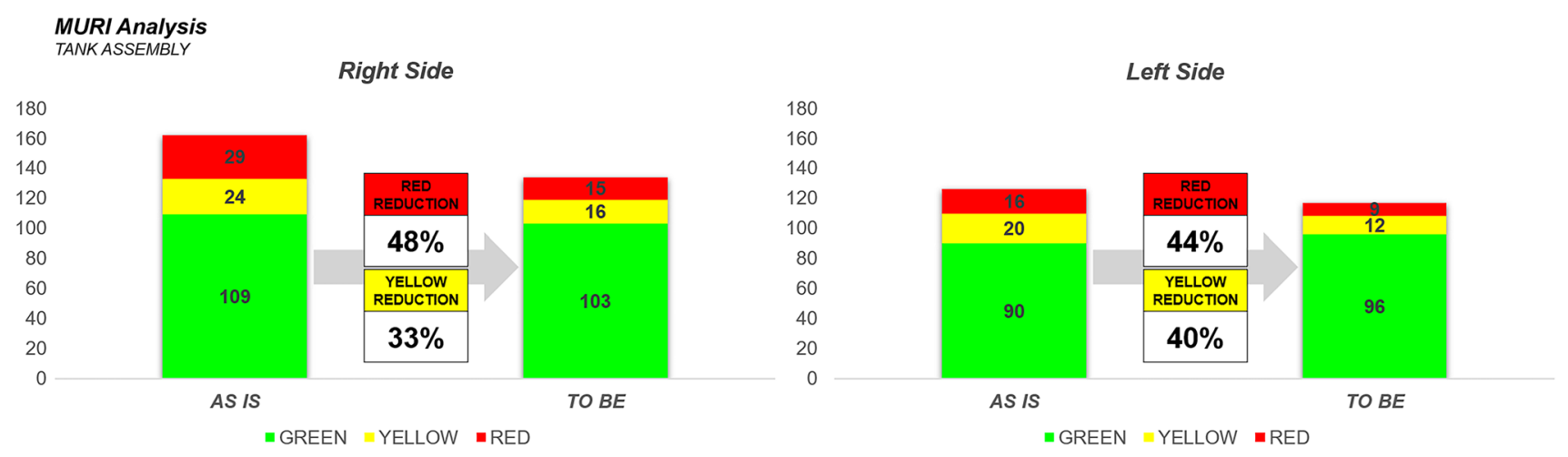

Fig. 9 Results of IoT-based MURI analysis

subjective bias; in other words, it is more difficult to outline all the risks because the observation alone does not unearth all dangerous positions. On the other hand, the results of the simulation-based analysis confirmed the observation made by De Felice and Petrillo [29]. Data coming from simulation made during the design phase are the most cautionary ones and report the highest red score rate. This may be due to inaccuracies that seldom lead to unnatural postures. Finally, the IoT sensors provide a balanced risk assessment, allowing to capture the real posture assumed by the operator through the continuous monitoring of his movements. As stated by De Felice and Petrillo [29], the use of wearable devices for motion capture represents an effective method to validate the workstation design from an ergonomic point of view.

The high prudence of the simulation consists in a great potential for designers to exploit among the KETs of I4.0; although very conservative, it allows preventing risks for the operator since the early design of the workstation, provided at the workshop already with high ergonomic efficiency. This latter aspect would lead to a significant reduction in costs for the implementation phase and an improvement in the working conditions of the operators. It is reasonable to affirm that applying innovative technologies in ergonomics evaluation ensures the assessment to be objective, detailed, and specific, with high accuracy and reliability level.

\section{Conclusions}

The paper presents a structured methodology that synergically merges WCM tools and I4.0 technologies to support the design of manufacturing equipment. Greater attention is paid to the identification and understanding of the problem, on which the design process is then based. The proposed approach effectively combines multi-domain design requirements and constraints to improve productivity, flexibility, and operators' wellbeing. The experimentation in the tractor assembly line of a multinational company, which follows the WCM program, allowed achieving significant benefits from both productive and ergonomic points of view.

The main strengths of the proposed methodology can be summarized as follows: (i) involvement of human factors in all steps of the problem-solving and design process, (ii) awareness of problems and knowledge of plant processes not based only on data but on direct observation and interaction with people, (iii) methodical and structured approach resulting from the effective combination of consolidated methods and tools, and (iv) greater motivation and engagement of different stakeholders.

On the other hand, the consideration of heterogeneous aspects, requirements, and constraints can give rise to an onerous optimization process aimed at finding the best compromise. Making the methodology a company standard also requires that knowledge becomes explicit and codified to streamline and speed up the design process. However, proper management of corporate knowledge is often lacking, especially in small and medium-sized enterprises.

The main limitation of the proposed methodology is the difficulty of implementation by those companies without expertise in the WCM paradigm, which implies a new way of thinking and working. For this aim, they will be involved in future experimentation.

Future works will also consider real-time measurements of human behavior and well-being aimed at the design of smart and adaptive solutions. For example, an increasing trend in human fatigue during the work shift could lead to a change in the equipment setting to offer greater support. Similarly, the decrease of the operator's concentration may prompt a digital assistant to show step-by-step, more detailed instructions.

Challenges and barriers originated from the interaction with advanced manufacturing systems will be also faced. For example, some studies have shown that the human-robot 
collaboration could induce greater stress in the operator if not adequately supported from an information point of view and that interaction with unfamiliar technologies (e.g., extended reality) could require a greater cognitive load. These aspects must necessarily be considered in the design of the equipment for workplaces 4.0 .

Open Access This article is licensed under a Creative Commons Attribution 4.0 International License, which permits use, sharing, adaptation, distribution and reproduction in any medium or format, as long as you give appropriate credit to the original author(s) and the source, provide a link to the Creative Commons licence, and indicate if changes were made. The images or other third party material in this article are included in the article's Creative Commons licence, unless indicated otherwise in a credit line to the material. If material is not included in the article's Creative Commons licence and your intended use is not permitted by statutory regulation or exceeds the permitted use, you will need to obtain permission directly from the copyright holder. To view a copy of this licence, visit http://creativecomm ons.org/licenses/by/4.0/.

\section{References}

1. Holweg, M.: The evolution of competition in the automotive industry. In: Parry, G., Graves, A. (eds.) Build to order. Springer, London (2008). https://doi.org/10.1007/978-1-84800-225-8

2. European Commission Directorate General Environment: The Potential of Market Pull Instruments for Promoting Innovation in Environmental Characteristics. COWI, Denmark (2009)

3. Chryssolouris, G., Papakostas, N., Mavrikios, D.: A perspective on manufacturing strategy: produce more with less. CIRP J. Manuf. Sci. Technol. 1(1), 45-52 (2008)

4. Michalos, G., Makris, S., Papakostas, N., Mourtzis, D., Chryssolouris, G.: Automotive assembly technologies review: challenges and outlook for a flexible and adaptive approach. CIRP J. Manuf. Sci. Technol. 2(2), 81-91 (2010)

5. Romero, D., Stahre, J., Wuest, T., Noran, O., Bernus, P., FastBerglund, A., Gorecky, D.: Towards an operator 4.0 typology: a human-centric perspective on the fourth industrial revolution technologies. In: Proceedings of the International Conferences on Computers and Industrial Engineering, pp. 1-11 (2016)

6. Ebrahimi, M., Baboli, A., Rother, E.: The evolution of world class manufacturing toward Industry 4.0: a case study in the automotive industry. IFAC-PapersOnLine 52, 188-194 (2019)

7. Sandeep, R., Panwar, N.: Identification of barriers in implementation of world class manufacturing (WCM) practices: a literature analysis. Int. Res. J. Eng. Technol. (IRJET) 3(5), 2363-2366 (2016)

8. De Felice, F., Petrillo, A., Monfreda, S.: Improving operations performance with world class manufacturing technique: a case in automotive industry. In: Schiraldi, M.M. (ed.) Operations Management. InTech, pp. 1-30 (2013)

9. Rauch, E., Linder, C., Dallasega, P.: Anthropocentric perspective of production before and within Industry 4.0. Comput. Ind. Eng. 139, 105644 (2020)

10. Gregori, F., Papetti, A., Pandolfi, M., Peruzzini, M., Germani, M.: Digital manufacturing systems: a framework to improve social sustainability of a production site. Procedia CIRP 63, 436-442 (2017)

11. Peruzzini, M., Carassai, S., Pellicciari, M.: The benefits of humancentred design in industrial practices: re-design of workstations in pipe industry. Proced. Manuf. 11, 1247-1254 (2017)
12. Asadi, N., Jackson, M., Fundin, A.: Implications of realizing mix flexibility in assembly systems for product modularity-a case study. J. Manuf. Syst. 52, 13-22 (2019)

13. Kolus, A., Wells, R., Neumann, P.: Production quality and human factors engineering: a systematic review and theoretical framework. Appl. Ergon. 73, 55-89 (2018)

14. Battini, D., Faccio, M., Persona, A., Sgarbossa, F.: New methodological framework to improve productivity and ergonomics in assembly system design. Int. J. Ind. Ergonom. 41(1), 30-42 (2011)

15. Caputo, F., Greco, A., Fera, M., Macchiaroli, R.: Digital twins to enhance the integration of ergonomics in the workplace design. Int. J. Ind. Ergonom. 71, 20-31 (2019)

16. Papetti, A., Scafà, M., Brunzini, A., Mandolini, M.: multiperspective ergonomic assessment approach for human centered workplace design. In: ADM 2019. LNME, pp. 675-685 (2020)

17. European Agency for Safety and Health at Work: EU-OSHA: Work-Related Musculoskeletal Disorders: Prevalence, Costs and Demographics in the EU. Publications Office of the European Union (2019)

18. Vink, P., Koningsveld, E.A.P., Molenbroek, J.F.: Positive outcomes of participatory ergonomics in terms of greater comfort and higher productivity. Appl. Ergon. 37, 537-546 (2006)

19. Azizi, A., Ghafoorpoor Yazdi, P., Hashemipour, M.: Interactive design of storage unit utilizing virtual reality and ergonomic framework for production optimization in manufacturing industry. Int. J. Interact. Des. Manuf. 13, 373-381 (2019)

20. Abdullah, T.A., Popplewell, K., Page, C.J.: A review of the support tools for the process of assembly method selection and assembly planning. Int. J. Prod. Res. 41(11), 2391-2410 (2003)

21. Dul, J., Neumann, W.: Ergonomics contribution to company strategies. Appl. Ergonom. 40, 745-752 (2008)

22. Falck, A.C., Rosenquist, M.: A model for calculation of the costs of poor assembly ergonomics (part 1). Int. J. Ind. Ergon. 44, 140-147 (2014)

23. Djapan, M., Macuzic, I., Tadic, D., Baldissone, G.: An innovative prognostic risk assessment tool for manufacturing sector based on the management of the human, organizational and technical/technological factors. Saf. Sci. 119, 280-291 (2019)

24. Peruzzini, M., Pellicciari, M., Gadaleta, M.: A comparative study on computer-integrated set-ups to design human-centred manufacturing systems. Robot Cim.-Int. Manuf. 55, 265-278 (2018)

25. Vukadinovica, S., Macuzica, I., Djapana, M., Milosevica, M.: Early management of human factors in lean industrial systems. Saf. Sci. 119, 392-398 (2019)

26. Brito, M., Vale, M., Leão, J., Ferreira, L.P., Silva, F.J.G., Gonçalves, M.A.: Lean and ergonomics decision support tool assessment in a plastic packaging company. Procedia Manuf. 51, 613-619 (2020)

27. Naranje, V., Naranje, A., Salunkhe, S.: Improving process performance with world class manufacturing technique: a case in tea packaging industry. In: International Conference on Innovative Design, Analysis and Development (2018)

28. Alonso, L., Rubino, E.M., Agustina, B., Domingo, R.: Latest clean manufacturing trends applied to a world class manufacturing management for improving logistics and environmental performance. Proced. Manuf. 13, 1151-1158 (2017)

29. De Felice, F., Petrillo, A.: Optimization of manufacturing system through world class manufacturing. IFAC-PapersOnLine 48, 741-746 (2015)

30. Romero, D., Stahre, J., Taisch, M.: The operator 4.0: towards socially sustainable factories of the future. Comput. Ind. Eng. 139, 106128 (2020)

31. Mrugalska, B., Wyrwicka, M.: Towards lean production in industry 4.0. Proced. Eng. 182, 466-473 (2017)

32. Di Pasquale, V., De Simone, V., Miranda, S., Riemma, S.: Smart operators: how Industry 4.0 is affecting the worker's performance 
in manufacturing contexts. Proced. Comput. Sci. 180, 958-967 (2021)

33. Fritzsche, L.: Ergonomics risk assessment with digital human models in car assembly: simulation versus real life. Hum. Factors Ergon. Manuf. 20(4), 287-299 (2010)

34. Alkan, B., Vera, D., Ahmad, M., Ahmad, B., Harrison, R.: A lightweight approach for human factor assessment in virtual assembly designs: an evaluation model for postural risk and metabolic workload. Procedia CIRP 44, 26-31 (2016)

35. Di Gironimo, G., Patalano, S.: Re-design of a railway locomotive in virtual environment for ergonomic requirements. Int. J. Interact. Des. Manuf. 2, 47-57 (2008)

36. Caputo, F., Greco, A., D'Amato, E., Notaro, I., Spada, S.: On the use of virtual reality for a human-centered workplace design. Proced. Struct. Integr. 8, 297-308 (2018)
37. Delangle, M., Petiot, J.F., Poirson, E.: Using motion capture to study human standing accessibility: comparison between physical experiment, static model and virtual ergonomic evaluations. Int. J. Interact. Design Manuf. 11(3), 515-524 (2016)

38. D’Orazio, L., Messina, R., Schiraldi, M.: Industry 4.0 and world class manufacturing integration: 100 technologies for a WCM-I4.0 matrix. Appl. Sci. 10(14), 4942 (2020)

39. Schonberger, R.J.: World Class Manufacturing: The Principles of Simplicity Applied. Free Press, New York (1986)

Publisher's Note Springer Nature remains neutral with regard to jurisdictional claims in published maps and institutional affiliations. 